DOI: $\underline{10.20472 / T E .2017 .5 .1 .006}$

\title{
USING CORPUS LINGUISTICS TO ANALYSE POST LESSON OBSERVATION FEEDBACK
}

\section{DOREEN SPITERI}

\begin{abstract}
:
The journey of the student teacher from the start of their Initial Teacher Education (ITE) pre-service programme to the end has been widely studied. Equally important is the journey of the teacher educator whose role in the learning experience of the student teacher is often a critical one as the teacher educator brings knowledge and experience to the learning relationship. This learning relationship is often mediated through language, one instance of which is the written feedback student teachers receive on their teaching practicum in the post lesson observation stage. This study explores the types of feedback given and the linguistic choices made by a teacher educator over a span of ten years in the context of pre-service teacher education based in an institution of higher education. A systematic, quantitative analysis was possible using a lexical analysis program supported by a qualitative analysis of the data.
\end{abstract}

\section{Keywords:}

teacher education, observation, teaching practice, teacher educator, corpus, analysis, linguistic, qualitative, quantitative, student teachers.

JEL Classification: 120, 121, 123

\section{Authors:}

DOREEN SPITERI, Universityof Malta, Malta, Email: doreen.sptieri@um.edumt

\section{Citation:}

DOREEN SPITERI (2017). Using corpus linguistics to analyse post lesson observation feedback. International Journal of Teaching and Education, Vol. V(1), pp. 67-84., 10.20472/TE.2017.5.1.006 


\section{Introduction}

\section{Research in the field of feedback to student teachers}

Research into the discourse of post observation conferences has tended to focus on oral feedback. One of the first reviews of the subject (Holland, 1988) spanning 30 years distilled the studies on supervisory conferences into three components: the perceived purpose, the relationship between the teacher and the supervisor in the conference situation, and the way in which information and data about the teacher's performance are used during the conference. No reference is made to written feedback. Since then, several other studies continued to look at the post observation conference: the form and substance of supervisory discourse between university supervisors and student teachers (Zeichner et al, 1988), the relevance of discourse analysis of supervisory conferences (Roberts, 1990), face-threatening acts and politeness theory (Roberts, 1991) the processes used by supervisors (Waite, 1992), an analysis of mentoring conversations with beginning teachers (Baron \& Strong, 2004), politeness strategies in delivering suggestions and advice (Vasquez, 2004), interactions between language teachers and their supervisors (Vasquez \& Reppen, 2007), language, power and control in post-observation interactions (Hyland \& Lo, 2006), the post-observation conference as a genre that student teachers need to negotiate (Copland, 2008), the impact of confirmatory and corrective feedback (Kurtoglu-Hooton, 2008), how topics and speaking rights are established and negotiated (Copland, 2011) among others.

Studies that looked at written feedback focussed on: logic and substance of discourse between university supervisors and student teachers (Zeichner \& Liston, 1985), features, style, and ways of giving advice and signalling progress (Spear et al, 1997), the linguistic characteristics of written supervision feedback reports (Glenwright, 1999), what student teachers consider to be the most useful processing tool for reflection (Smith \& Lev-Ari, 2005), the most effective forms of feedback according to student teachers (White, 2007), the content of the feedback (Akcan \& Tatar, 2010), using critical discourse to capitalize on opportunities to develop adaptive teaching expertise (Soslau, 2012), among others.

Mainly from the studies above and from other studies that focus on feedback, including that given by university tutors, some categories of types of feedback have been proposed. Feedback has been categorized as factual, prudential, justificatory and critical discourse (Zeichner \& Liston 1985); as authoritative advice and cooperative advice (Spear et al 1997); as expressing approval, expressing reservations or criticism, and giving advice or directives (Glenwright 1999); as confirmatory or corrective (Kurtoglu-Hooton 2004 following Egan, 2002); as descriptive, questioning, evaluative and advisory (Burton et al 2002); and as reflection, direction, evaluative and relational (Farr, 2007) among other categorizations. The differences tend to be ones of preferred terminology rather than distinctions, and there is a great deal of overlap among the terms. However, a study that stands out for its methodology is Farr's (2007) 
study that reaches conclusions about categories of feedback by using corpus linguistics to analyse the post-observation feedback. The study reported here takes Farr's work as the point of departure and similarly uses corpus linguistics to explore the types of feedback given and the linguistic choices made by a teacher educator over a span of ten years in the context of pre-service teacher education based in an institution of higher education. This systematic, quantitative analysis was possible through the use of a lexical analysis program supported by a qualitative analysis of the data.

\section{Theoretical framework}

Though not conducted strictly as a self-study, the paradigmatic framework adopted here shares some elements of self-study research. Taking LaBoskey's (2004) five characteristics of self-study methodology, this study can be described as self-initiated and self-focussed, and aimed at improving my own practice as well as linking my practice to current understandings in teacher education of how best to prepare student teachers. It also aimed to locate any living contradictions (Whitehead 1993) between my actual practice, to better align [my] teaching practices with [my] teaching intentions (Loughran 2007, p.12). The knowledge generated is, in the first instance, of use to my practice, and it should contribute to the improvement of the practice of others as it produces public knowledge of practice (Pinnegar, Hamilton, \& Lynn, 2009, p. 99).

While self-study research tends to be predominantly but not exclusively qualitative in nature, this study uses quantitative methods, which still make demands on the validity and trustworthiness of the process. The statistical linguistic analyses conducted make for a transparent and systematic research process (Bullough and Pinnegar, 2004, pp. 340-341) however, the qualitative reflection on the analyses was an individual effort, missing the critical collaborative enquiry, which is a characteristic of self-study.

\section{Contextual background of the study}

\section{The teaching practice}

The context of this study is somewhat particular as this ITE university-based degree course is still in the process of establishing partnerships with schools and setting up mentoring support systems despite being in existence since 1981. In the absence of a school mentor, the level of support that student teachers can expect on their field placement varies widely because there are no specifically chosen or trained teachers as mentors. There is a cooperating teacher whose role is not described and the support they give could range from minimal to highly valued (Smith \& Spiteri, 2013). The reasons for this are many and varied but it is beyond the scope of this study to explore here. The upshot is, however, that the university tutor or supervisor is the only point of reference for the student teacher. It is they that observe lessons and hold post-observation conferences and write reports.

The teaching practice lasts six weeks and four unannounced visits by two university tutors take place. A visit normally consists of one observed lesson (around 40 or 45 
minutes) followed by a conference (around 30 minutes) between the student teacher and the university tutor only, on site at the school. This could take place immediately following the observed lesson or later in the day, at university, if the student teacher is teaching again, or if the university tutor has other visits to conduct.

Guiding the post-observation session is a one-page pro forma in the form of a checklist of competences and a list of criteria organized around three themes: Planning and Preparation, the Teaching and Learning process (the lesson), and Communication, Classroom Management and other Professional qualities. Under each heading is a list of indicators further expounding on the headings and a system of ticking off on a three-point descriptive scale of Marginal, Satisfactory, and Unsatisfactory. In addition, a lined page is available for a qualitative, discursive response on the observed lesson and any other related aspects identified by the tutor as necessitating comment. The two strike a balance between the need for structure and standardization among all the university tutors, and open-ended comments that allow the tutors to respond freely to the particularities of the situation. This document, in the shape of a booklet, is retained by the student teacher; on occasions when the tutors cannot complete the report on site, it is returned to the student teacher as expediently as possible. The booklet therefore contains reports written by more than one university tutor, however, as this study focuses on the researcher's own development, only the two reports written by the researcher out of the four were selected for analysis.

Each of the four visits, and consequently each report, is intended to support the student teacher but also assess performance. The tutors therefore tread an uneasy ground between formative and summative roles: suggestions and recommendations are made, however, the visit is also formally assessed as having constituted a Marginal, Satisfactory, or Unsatisfactory performance. There has been much heated debate within the faculty about this practice, however, at the time of writing the policy still stands.

After the practicum, a Board of Examiners including the two tutors, considers the four reports and a final decision regarding the student teacher's overall performance is reached.

\section{Method}

Selected for this study were 36 feedback reports given to 18 student teachers, 9 each from two teaching practice periods separated by a ten years. The selection of students was based on the fact that in the first teaching practice period, I was tutor for 9 student teachers and so selected them all; for the second, I chose the first 9 students on the list. The list is compiled according to the location of the school the student teachers taught in. The two cohorts of student teachers had all completed their teaching practice successfully.

The profile of the student teachers was largely similar: they all were young university students typically aged $18-22$, from the same country, of the same nationality, and 
all were following an initial teacher education course, on a full-time basis, in English language teaching, specifically to teach the $11-16$ age bracket of learners in mainstream education.

The data - the handwritten feedback reports - were typed out to permit linguistic analyses using a lexical analysis tool - Wordsmith (Smith 2004) - which consists of an integrated suite of programs for looking at how words behave in texts (Scott, 2014). Data can be analysed for a range of purposes: to find out the most frequently occurring words, the words that typically cluster together and form patterns, the key words in a text, and concordances. The lexical analysis tool also allows one to explore sentence patterns and identify the position of search words in sentences and paragraphs.

The data inputted resulted in a small corpus of tutor written feedback of 12,378 words. Additionally, a manual qualitative analysis followed that analysed the units of feedback according to categories found in the literature. For the purpose of the analysis, a 'unit' was considered to be a sentence or more, that dwelt on one issue. The researcher purposefully avoided parsing the data into chunks that were either descriptive or evaluative or advisory as this would skew the thrust of the feedback being given. Consequently, a chunk of feedback that focussed on one issue and possibly contained diverse elements was considered as one unit of feedback.

The two sorts of analyses - corpus and qualitative - were intended to complement each other and drive each other: the frequency counts, for example, served to identify patterns which led to a closer look at the data. The manual categorization then drove linguistic analyses such as concordances which served to identify other patterns of language usage.

\section{Findings and discussion Length of reports}

The following are some statistical data about the written feedback which will be referred to as Data Set $A$ representing data collected at the first point in time. One of the first differences that stands out (fig. 1) is the difference in length of written reports between the two data sets. The later reports (Series 1), are consistently longer than the early reports (Series 2 ). 
Figure 1. Word count of each feedback report grouped by data sets - A and B.

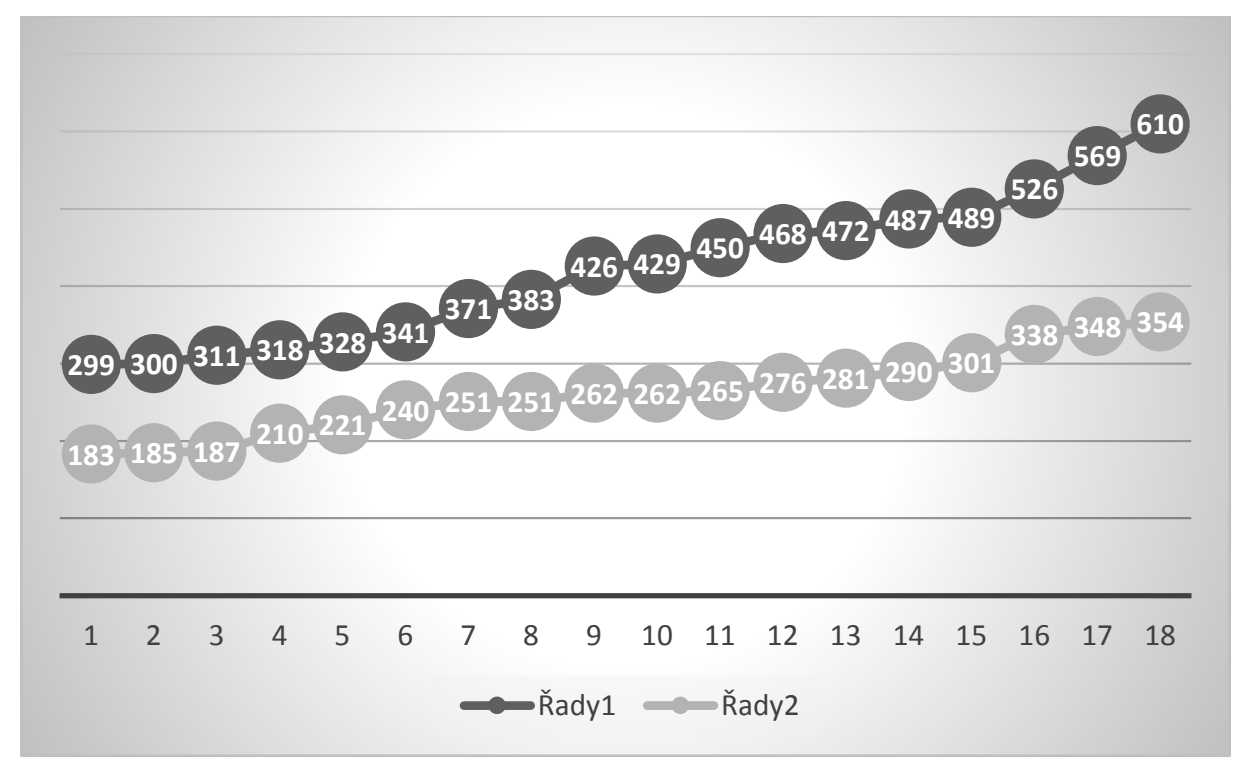

Source: Own

This increase may be attributed to two reasons: a conscious decision that responded to changing local realities and a greater sensitivity to the dynamics of the post lesson conference. Student teachers who failed their practicum have on occasion officially challenged the written assessment given by the university tutors claiming that the written reports did not contain sufficiently strong reasons to justify their failing grade. The oral feedback, by its very nature, cannot be factored into the equation and in cases where the strongest evaluation was given verbally and tutors held back from being unequivocal in the written reports, their assessment was questioned and found insufficient to fail a student teacher. To counter this, the understanding among faculty staff was to beef up the written feedback to sufficiently support the summative assessment made.

The other reason for the increased length was the slowly growing realization that the tension inevitably characterizing the post-observation conference, adversely affected some student teachers' disposition to absorb what was being discussed (Brandt, 2008). Glenwright (1999, p.60) talks about the fraught and intensely human nature of the whole supervisory exercise which offers a scenario where teacher self-esteem may be carefully enhanced and nurtured or unwittingly destroyed. I became aware over the first years that the sensitive nature and power issues revolving around the post-observation feedback could impede the student teachers from taking in the oral message fully. This anxiety is related to the fact that each observed lesson is evaluated as either satisfactory, not satisfactory, or marginally satisfactory. The summative nature of this and the effect on the student teachers is quite overwhelming, such that it has happened that at the end of a detailed feedback conference, the student asks the tutor whether the visit was a pass or a fail - an experience reported by Stevens and Lowing (2008) in their research. Consequently, the written reports came to constitute a valuable resource and record of the feedback given to the student 
teacher that could be pored over at a later moment, and possibly in a calmer frame of mind.

\section{Categories of feedback that emerge from both data sets}

A manual analysis of the 36 written feedback reports (12,378 words) resulted in the following two broad functional categories - Confirmatory and Corrective (Egan, 2002) - which are further subdivided into other related categories:

Table 1 All feedback categorized into 3 main types
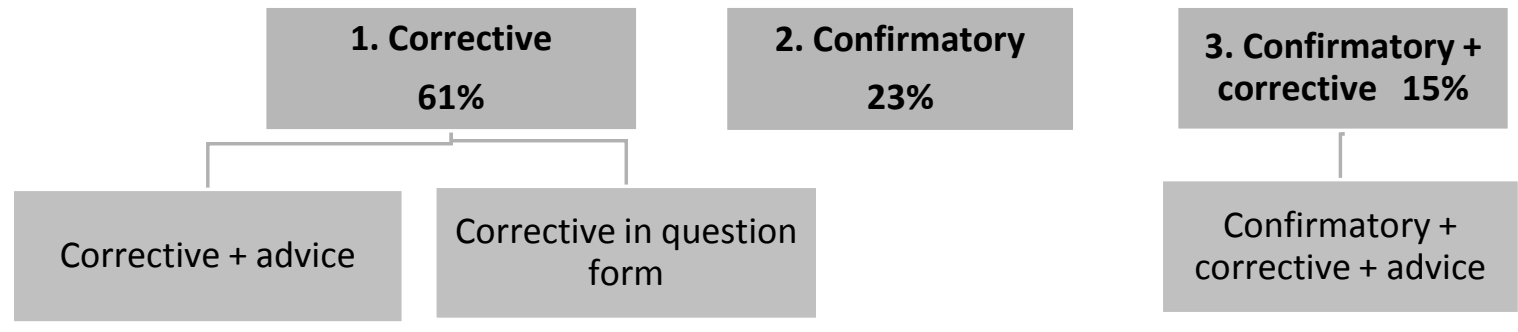

Source: Own

Corrective feedback is feedback which requires the receiver to change their practice and align it to practices required by the programme or institution. In essence, it is a form of criticism that can range from a reproach (Your lesson evaluations are not updated, neither are the learner profiles) to a recommendation (I think you needed to do something about students forgetting their book).

Confirmatory feedback seeks to approve what the student teacher is doing (Your hand-outs are attractive and motivating); it serves the purpose not only of showing appreciation for good practice, but also to confirm what constitutes good practice

The table shows that aside from units of feedback that were either corrective or confirmatory in nature, another category resulted from the analysis - feedback that contained a mixture of a confirmatory and a corrective (The use of the picture as an introduction worked well, but you did not link it to the poet of the sonnet). When the percentage value in this last column (15\%) is shared between the two main categories of confirmatory and corrective, one could say that all the written feedback given is made up of approximately $30 \%$ that is positive and expresses approval of the student teachers' practice, while corrective feedback that expresses reservations or indeed criticism, makes up the remaining $70 \%$. The percentage of confirmatory feedback compares very well to that found by Glenwright in his analysis of three supervisors' written reports (1999 p.67).

\section{Categories of feedback compared for the early and recent data sets.}

The graph below shows in greater detail the type of feedback given and differences between the two points in time when this feedback was written. 
Figure 2. Categories of feedback compared for both data sets

\section{Data Set A, $\square$ Data Set B}

CORRECTIVE + ADVICE e.g. Work into the Scheme of Work the repair/correction of writing tasks.

CONFIRMATORY e.g. You walk around the class - good.

CORRECTIVE e.g. You really should know all the students' names.

CONFIRMATORY+CORRECTIVE+ADVICE e.g. You keep a record of work, good, you also need to show when to collect hw.

CONFIRMATORY+CORRECTIVE e.g. You have already assigned hw and corrected it, but it's very disappointing to see that you are not... CORRECTIVE-QUESTION FORM+ADVICE e.g. Why do not your lesson plans show the duration of each stage of the lesson?

CORRECTIVE+QUESTION FORM e.g. Do show what resources you are using. Where did the listening comprehension come from?

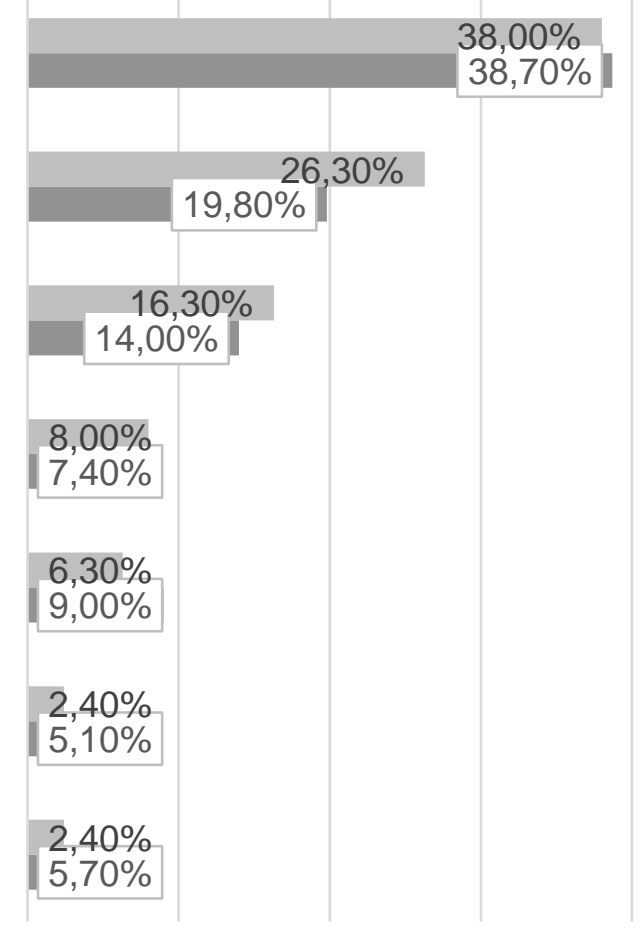

Source: Own

Over the years there appears less confirmatory feedback (19.8\% in Data Set B, 26.3\% in Data Set A) and more confirmatory feedback that is qualified with a corrective comment such as: The use of visuals and choice of visuals was good but the approach again did lead to chatting among students and not all students were focussed and on task (9\% in Data set B, 6.3\% in Data set A).

A variation on the last category above of a confirmatory comment qualified by a corrective, sees the addition of advice typically following the corrective. For example: Your introduction to countable/uncountable nouns was good because you used what they know - a pity you used 'pasta' as an example, 'salt' would have been a better example.

A slight decrease is recorded in the amount of corrective statements made in the teaching practice reports. At the early stages as a teacher educator, this made up $16.3 \%$ of all comments, compared to $14 \%$ ten years later. Typical corrective statements are the following: Time was obviously an issue as the lesson aims could not be achieved and Your lesson objectives often sound like tasks students will be doing, not learning objectives.

Much of the feedback is made up of corrective comments followed by advice such as: Organize your whiteboard work better, use it to jot down what the students suggest, 
then clean up in preparation for when you next need it. Over the span of 10 years, the amount of this type of corrective feedback and advice given has remained largely similar at around $38 \%$.

What has more than doubled however is the use of question forms that function more as correctives than genuine questions but which also have the purpose of encouraging reflection: Do you have to hand out the sheets yourself? Why not use the time to manage some uncooperative students? Bunton et al (2002) identified this category as Questioning/Reflective in their study of 27 tutors' written post observation feedback, typified by genuine questions or inviting the student teacher to speculate on choices made, for example: Why did you then use........ Just to keep it general initially? (p.240). Spear et al (1997) categorized these simply as suggestions (p.276).

A variation on this way of giving instruction through questions is the addition of advice, for example: Why collect their school work? - it was far more important to class correct it to check understanding of the reading text. This approach of encouraging reflection while giving direction and advice made up almost $11 \%$ of the written feedback of the second data set whereas early on in my the percentage stood at just under $5 \%$. However, when I reflected on this data some doubts arose about the assumed benefits of question forms that purportedly encourage reflection. They seemed more akin to disguised criticism than genuine questions. Indeed, they could be read in an incredulous questioning tone which renders them quite harsh. It would be useful to follow up this hypothesis by running such statements past student teachers for their opinion.

Also of interest is the addition of a coda at the end of the written report. In 15 out of 18 reports that were handed to student teachers in the second data set, there was a closing sentence that wrapped up the report and made a general comment often of an encouraging nature and clearly intended to offset the evaluative load of the written report such as: Although today's performance did not meet the required standards, I feel the issues can be resolved with reflection and reference to the literature. In the early Data set, this appeared only in 6 out of 18 reports.

One can conclude therefore that over the years there has been no change in the type of feedback given, but the difference lies in the frequency: fewer confirmatory statements, an increased occurrence of confirmatory statements qualified by a corrective one, and an increased use of questions rather than statements. This suggests that as a teacher educator writing feedback on observed lessons, I temper corrective statements by preceding them with a positive comment and also by using a question form. One might therefore infer that although the amount of correctives has remained largely the same, this has now been balanced with the addition of a confirmatory comment in the same sentence or by the use of a question form that replaces that corrective statement. 


\section{Differences in choice of words across a ten-year span}

Having established that there were differences over time in the amount of praise given to student teachers, of related interest was exploring whether the lexis had changed over the span of 10 years. Again using the lexical analysis software, words from the two sets of data that stood out because of a significant $(0.001)$ difference in the frequency of use were computed. The figures refer to the frequencies.

Table 2. Words from the two data sets

Data set A

Data set B

\begin{tabular}{rcc}
\hline activity & 5 & 38 \\
\hline check & 1 & 19 \\
\hline learning & 5 & 27 \\
\hline listening & 6 & 33 \\
\hline objectives & 20 & 2 \\
\hline record & 25 & 5 \\
\hline scheme & 23 & 6 \\
\hline very & 19 & 6 \\
\hline video & 0 & 13 \\
\hline work & 55 & 30
\end{tabular}

Source: Own

The statistical result above led to the computation of concordances, again using Wordsmith, to better understand how the words behaved in the texts, although a completely satisfying explanation was not always available. For instance, the use of the word activity has mushroomed over the years; it can only be surmised that in the feedback more specific advice is being given to specific classroom events. This conclusion can be reached because the early data set does not show a synonym for activity such as task or exercise.

An area of concern regards the attention given by student teachers to developing their learners' listening skills. Computing a concordance for listening showed that it appeared in a cluster invariably with skills and this echoes perfectly my concern that student teachers focus excessively on grammar to the exclusion of listening skills which tend to be side-lined during lessons.

The increased use of learning could indicate a shift in the discourse towards the effect of the teaching on the school learners, and this ties in with the next word in the table - objectives - which virtually falls out of use in the recent data set. Trawling through the frequency lists shows a move away from objectives to learning outcomes signalling a growing concern with the effectiveness of student teachers' lessons.

Check appears only once in the first data set and the concordance for the uses of it in the second data set shows that check is largely used as in cross check indicating that the use of pedagogical register associated with questioning techniques in the feedback reports. 
It is interesting to note that in the first data set there was no mention of the use of video in the feedback reports while in the later data it occurs 13 times, clearly reflecting the technological resources now available in classrooms.

The next two items on the comparison of data list are related: record and scheme refer to record of assessment, record of work, and scheme of work - all documentation that student teachers are expected to have. Early on in my work as a teaching practice supervisor I had not anticipated the difficulties the student teachers could have in the practice of mapping out lessons in a scheme of work, recording how much ground was actually covered in lessons, and taking note of learners' progress. The input on this during lectures subsequently grew to address this need such that criticism on these aspects has decreased considerably.

How something is said is as important as what is said and meaning is signalled by particular choices of words (Stubbs 1996). Corpus analysis allows the identification of patterns and use of language which will further describe the linguistic choices I made as shown below.

\section{Confirmatory feedback - how was this expressed}

It is widely accepted that feedback - whether spoken or written - should have elements that are positive and negative. Indeed, student teachers have been reported as expecting evaluation and to be told clearly what they were strong in and what needed improving (Bunton et al, 2002), (Copland, 2008). The corpus showed that the word 'good' - typically associated with praise - occurred 43 times in Data set A and 21 times in B. Indeed, analyses show that 'good' appears 2 times per thousand words, compared to 9 times per thousand words in the early stage of my work as teacher educator.

Related to the above are the findings from a search for 3-words clusters among the confirmatory feedback. There are several variants of you do well, you did well, you do well to in the recent data set. This particular cluster does not appear once in the first set of data suggesting that the use of good was substituted with variants of the phrase you do well as this occurred almost twice per feedback report as opposed to once every two reports in Data set $A$.

Analysing the confirmatory feedback also showed that 'you' and 'your' were the top two most frequently used words in Data Set A whereas in the later data these two words were among the top 5 . It appears that initially the direct pronoun and possessive pronoun were used marginally more frequently than in the later data set. Typically, praise or confirmation of good practice appears as:

Your student profiles show that you know your learners and you care about them. Your lesson plans are quite detailed; 


\section{Corrective feedback - how was this expressed \\ Tone of correction feedback}

Corrective feedback in all its forms - whether modified with advice or in question form or purely corrective with implied advice - amounts to $61 \%$ of the units of feedback, or $68 \%$ if one adds the corrective comments that are part of a confirmatory-pluscorrective comment.

Undoubtedly, this is the most sensitive part of the written feedback for student teachers and it is intended to help them adopt different practices or adapt current practices so they teach in ways that match the expected competencies in the pro formas and assessment criteria.

It must be remembered that this study looks at written feedback in isolation from the spoken feedback which are often complementary in function. The written feedback contains little phatic discourse, is largely evaluative in nature and scores low on encouraging reflective thinking partly because of the monologic mode (Farr, 2007).

Analyses of the corrective feedback shows that the style and content match that reported in the literature. Farr (2007) found that written feedback was strongly directional in function and direct in style. For style, compare the following example:

Tape quality was poor. This had a negative effect at this level, especially. Check before use. (Farr, 2007)

with

Next, the students worked on a hand-out with the uninviting title of 'The first conditional' (own data).

\section{Function of corrective feedback}

In terms of function, part of the purpose of feedback is to support and guide student teachers by giving advice and alternative ways of teaching more effectively. Of 215 units of corrective feedback in 2014, 70\% came with advice and in many instances of the rest of the corrective feedback, the advice was implied as in the following: By this stage [of the lesson], we seem to have lost the holiday theme. The sentence on the IWB weren't all related to holidays. This marks an increase from the pattern in the early point in time when $64 \%$ of the corrective feedback given was accompanied with specific advice for improvement, while the rest was mainly pointing out reservations or criticism, although again this distinction was at times blurred: feedback that has been categorized as corrective had elements of implied advice. For example: Your approach was not a discovery approach, you virtually told the students the [grammatical] rules.

\section{Grammar of corrective feedback - imperative forms}

The focus of this section is the verbs and tenses used in corrective and evaluative feedback. A manual coding of the both sets of feedback reports resulted in the identification of 417 units of feedback that contained an element of evaluation and 
correction - either by itself or accompanied by advice and direction. In these 417 units, the verb do in the imperative form stands out, both in the affirmative as in $\underline{D o}$ share your Learning Outcomes with the students, and in the negative form: $\underline{\text { Do not }}$ stand close to the student speaking because she will not raise her voice for all to hear. However, the imperative form also appears in several other verbs as can be seen in the first column of the table below.

\section{Table 3. Imperative forms}

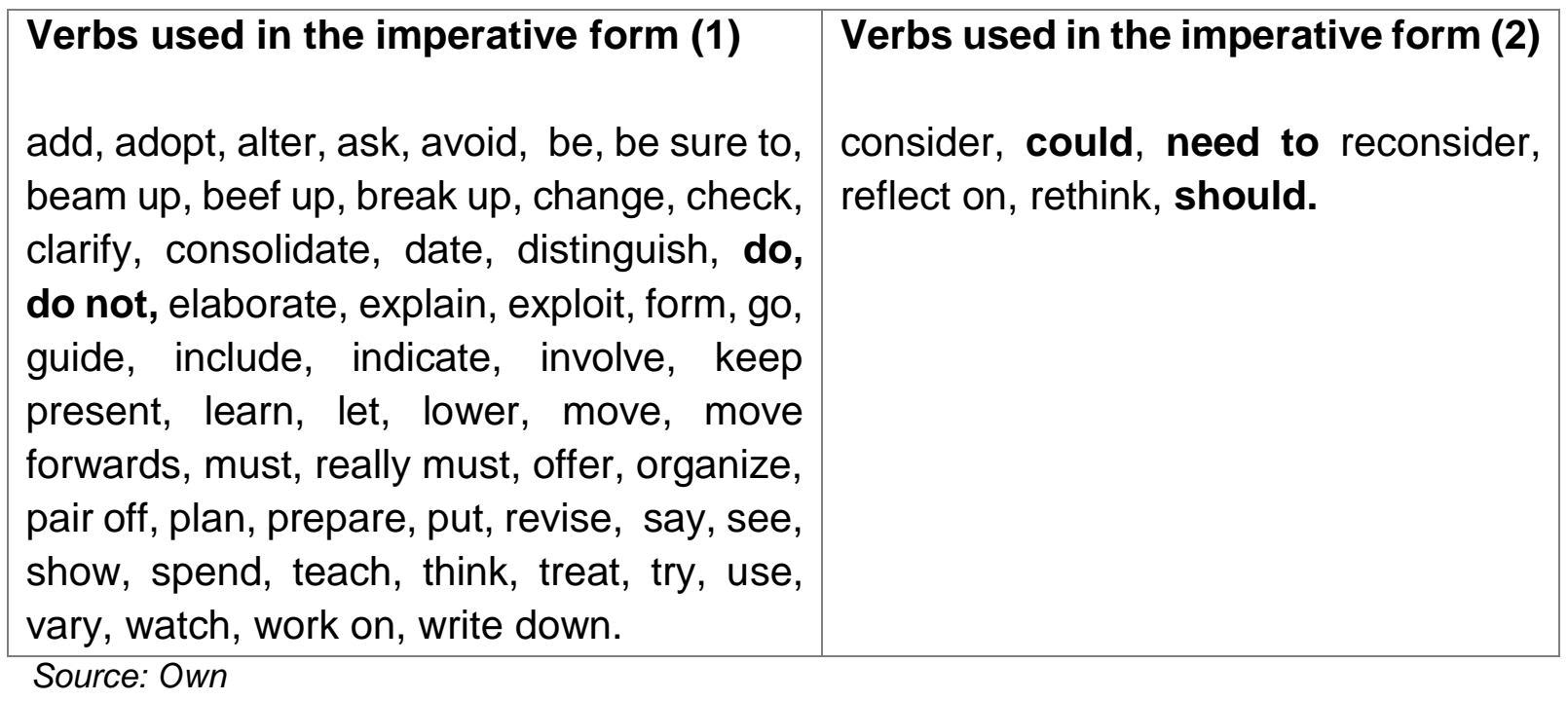

Modal items such as could and could have, should and need(ed) ((2) above) were among the items that appeared frequently in this small dataset, and they seem a little less severe than the other verbs in the imperative form. At times however, the thrust of these verbs is further bolstered by the intensifier really as in:

You really needed to conclude and wrap up the lesson and consolidate the teaching point.

The whole class approach really did not work.

You really must approach this very differently and Penny Ur's book is helpful here.

Inasmuch as written reports encourage reflection - and studies have shown this to be little - some verbs encouraging some form of reflection can be found in the data (2). Some examples of units of feedback encouraging reflection:

Consider first using the visuals silently while pairs of students prepare their answers and then have a quick assessment check, whole class.

Reflect on your management strategies; no need to escalate to a reprimand go through stages first as I explained to you.

Please reconsider how to deal with students' difficulties. Supplying the answers yourself is NOT the way to go about it. 


\section{Grammar of corrective feedback - advisory forms}

The following lists all the examples of giving advice using a far less direct approach than addressing the student teacher directly, and opting instead for the neutral, passive form.

It is advisable to

It's best not to

It's necessary to

It is not enough to

It's best to

It is useful to (4 times)

For example:

When taking answers from students, it's best to stand next to the student who is furthest AWAY so that the speaker raises her voice for you (and all the class) to hear.

Contrast this with an identical piece of advice on the same issue, this time using the imperative negative form; it comes across as harsher and more forceful.

Do take up the advice I gave during my first visit: do not stand close to the student speaking because she will not raise her voice for all to hear.

\section{Changes in personal stance to giving corrective feedback}

Since one of the aims of this paper is to trace any changes in the linguistic choices made when writing feedback, a basic frequency count among the verbs in the units categorized as corrective, gave the following result:

Table 4. Frequency and changes in use

$\begin{array}{ccc}\text { Data set } A & \text { Data set } B & \text { Change } \\ \text { all } 18 \text { reports } & \text { all } 18 \text { reports }\end{array}$

\begin{tabular}{rccl}
\hline could/could have & 5 & 23 & +18 \\
\hline would/would have & 5 & 19 & +14 \\
\hline I think & 4 & 15 & +11 \\
\hline really & 3 & 14 & +11 \\
\hline consider & 0 & 9 & +9 \\
\hline need to /needed to & 17 & 24 & +7 \\
\hline must & 4 & 9 & +5 \\
\hline reflect on & 0 & 4 & +4 \\
\hline do & 10 & 12 & +2 \\
\hline I would & 6 & 0 & -6 \\
\hline should & 23 & 18 & -5 \\
\hline please & 6 & 4 & -2
\end{tabular}




\begin{tabular}{llll} 
this is not acceptable & 1 & 1 & $/$ \\
\hline I strongly advise you & 1 & 1 & $/$ \\
\hline Source: Own
\end{tabular}

Starting from the top of the table, one notes the increased use of modal verbs could/could have and would/ would have that are typically used to talk about situations that are different from what actually happened. A closer examination of the data reveals that later in my development as teacher trainer, I am offering solutions and different scenarios to the student teachers as alternative ways of teaching to the ones observed. The fourfold increase in the use of could particularly attests to proposals of other ways of being and doing that student teachers could consider.

I think in Data Set B stands out, indicating an increased preference for stating a personal viewpoint rather than an authoritative statement. It could also be signalling that the proposing of a suggestion given that some aspects of the dynamics of a class are often hidden to the outsider. This seems to be mirrored in the non-occurrence of the phrase I would in the same data set which suggests a move away from portraying oneself as an expert who has all the answers.

The increased use of must in the same data set, in tandem with the decreased use of should suggest a move to a stronger expression of obligation. It is not clear whether the much more frequent use of the intensifier really is related to this as in: With some time left you did the first activity from the Matrix unit but you really should have followed the course book which correctly accompanied the music with a task. Also more frequent is the use of need to/needed to which is further evidence of the occurrence of advice in recent feedback reports.

A change in approach is evident in the use of verbs that encourage some form of reflection. In the first Data Set, the verbs consider and reflect do not appear in any report, whereas in the later Data Set they appear a combined 13 times.

It may also be interesting to note that in both sets of data, a very strong corrective this is not acceptable and I strongly advise you not to - was used only once in each set.

\section{Conclusion}

The purpose of this study was to explore, categorize and reflect on changes in lexical choices over the span of 10 years in the practice of writing post observation feedback to student teachers on their practicum. This reflection was rendered systematic through the creation of a mini corpus which allowed the exploration of the textual data statistically. Consequently two areas stand out: firstly, the great usefulness of a corpus that enables analyses otherwise impossible, and secondly the usefulness of reflecting on one's actions and scrutinizing for living contradictions. The study has shown that the quality of supervisory feedback has improved along the journey as a teacher educator. If encouraging reflection among student teachers is desirable, then the later feedback reports show that this goal is increasingly being met more effectively through 
the conscious choice of language that meets that goal. Moreover, the types of feedback given in the second data set, match the preferences expressed by student teachers for suggestions, advice, areas for improvement, praise, and encouragement (Bunton et al, 2002). However, the study would have benefitted from collaboration with colleagues whose interpretation of the categorizations of feedback would have added reliability. Also, the views of the student teachers would have added a useful dimension. Of relevance to other research is the labour-intensive aspect of data input. Other teacher educators embarking on similar journeys would benefit from opting from the outset for electronic means of recording written feedback as this would render the process significantly easier and allow for more frequent reflections on one's practice. Moreover, this would in time generate a valuable database from teacher educators in various sites which the professional community can study to further deepen the developmental processes experienced by teacher educators.

\section{References}

Akcan, S. \& Tatar, S. (2010). An investigation of the nature of feedback given to pre-service English teachers during their practice teaching experience. Teacher Development, 14 (2): 153-175. https://doi.org/10.1080/13664530.2010.494495

Baron, W. \& Strong, M. (2004). An analysis of mentoring conversations with beginning teachers: suggestions and responses. Teaching and Teacher Education, 20, 47-57. https://doi.org/10.1016/j.tate.2003.09.005

Brandt, C. (2008). Integrating feedback and reflection in teacher preparation. ELT J, 62 (1): 37 - 46. https://doi.org/10.1093/elt/ccm076

Bullough, R. \& Pinnegar, S. (2004). Thinking about the thinking about self-study: An Analysis of Eight Chapters, in Loughran, J. J., Hamilton, M. 311 L. LaBoskey, V. K, Russell, T. International Handbook of Self-Study of Teaching and Teacher-Education Practices. Dordrecht, Kluwer Academic Publishers. https://doi.org/10.1007/978-1-4020-6545-3_9

Bunton, D., Stimpson, P., \& Lopez-Real, F. (2002). University tutors practicum observation notes: format and content. Mentoring and tutoring: partnership in learning, 10 (3):233-252. https://doi.org/10.1080/1361126022000037060

Copland, F. (2008). Deconstructing the discourse: understanding the feedback event. In S. Garton \& K. Richards (Eds), Professional encounters in TESOL: discourses of teachers in training (pp. 2441). Basingstoke,: Palgrave Macmillan. https://doi.org/10.1057/9780230594173_1

Copland, F. (2011). Legitimate talk in feedback conferences. Applied Linguistics, 33 (1):1 - 20. https://doi.org/10.1093/applin/amr040

Egan,G. (2002) The Skilled Helper: A Problem-management and Opportunity-development Approach to Helping. Brookes/Cole Publishing Company.

Farr, F. (2007). The Discourse of Teaching Practice Feedback. A Corpus-Based Investigation of Spoken and Written Modes. New York London: Routledge.

Glenwright, P.D.L. (1999). The discourse of written teaching practice supervision reports: linking language and methodology. Asia Pacific Journal of Language in Education, 2 (2): 57-87.

Holland, P. (1988). Implicit assumptions about the supervisory conference: a review and analysis of the literature. Journal of Curriculum and Supervision, 4 (4):362-379. 
Hyland, F. \& Lo, M. (2006). Examining interaction in the teaching practicum: issues of language, power and control. Mentoring and tutoring:partnerships in learning, 14 (2): 163 - 186. https://doi.org/10.1080/13611260500493535

Kurtoglu-Hooton, N. (2004). Post observation feedback as an instigator of teacher learning and change. In IATEFL TTED SIG Newsletter.

Kurtoglu-Hooton, N. (2008). The design of post-observation feedback and its impact on student teachers. In S Garton \& K Richards (eds), Professional encounters in TESOL: discourses of teachers in training (pp. 24-41). Basingstoke,: Palgrave Macmillan. https://doi.org/10.1057/9780230594173_2

LaBoskey, V. K. (2004). The methodology of self-study and its theoretical underpinnings (pp. 817-869) In J.J. Loughran, M.L.Hamilton, V.K. LaBoskey, \& T. Russell (Eds.) International handbook of self-study of teacher education practices. Dordrecht: Kluwer Academic Publishers. https://doi.org/10.1007/978-1-4020-6545-3_21

Loughran, J. (2007). Researching Teacher Education Practices. Responding to the Challenges, Demands, and Expectations of Self-Study. Journal of Teacher Education, 58 (1): 12-20. https://doi.org/10.1177/0022487106296217

Pinnegar, S., \& Hamilton, M.L. (2009). Self-Study of Practice as a Genre of Qualitative Research. Theory, Methodology, and Practice. Springer

Roberts, J. (1990). The relevance of discourse analysis of supervisory conferences: an exploration. Proceedings of The Annual meeting of the Council of Professors of Instructional Supervision, Athens, 1-31.

Roberts, J. (1991). Face-threatening acts and Politeness Theory: contrasting speeches from supervisory conferences. Proceedings of The Annual Meeting of the American Educational Research Association, Chicago, 1-21.

Scott, M., (2014). WordSmith Tools version 6, Liverpool: Lexical Analysis Software.

Smith, K., (2010). Assessing the practicum in teacher education - do we want mentors and student teachers to agree? Studies in Educational Evaluation, 36 (1-2), 36-41. https://doi.org/10.1016/j.stueduc.2010.08.001

Smith, K. \& Lev-Ari, L. (2005). The place of the practicum in pre-service teacher education: the voice of the students. Asia-Pacific Journal of Teacher Education, 33 (3):289-302. https://doi.org/10.1080/13598660500286333

Smith, L. \& Spiteri, D. (2013). A Tale of Two Cities: a comparison of the PGCE Secondary English Programmes at the Universities of Bristol and Malta. English in Education, 47 (3):213-228, 2013. https://doi.org/10.1111/eie.12027

Soslau, E. (2012). Opportunities to develop adaptive teaching. Teaching and Teacher, 28(5), 768-779. https://doi.org/10.1016/j.tate.2012.02.009

Spear, M., Lock, N.D., and McCulloch, M. (1997). The written feedback mentors give to student teachers. Teacher development: an international journal of teachers' professional development, 1, 2:269-280.

Stevens, D. \& Lowing, K. (2008). Observer, observed and observations: Initial teacher education. English tutors' feedback on lessons taught by student teachers of English. English in Education 42(2): 162-198. https://doi.org/10.1111/j.1754-8845.2008.00015.x

Stubbs, M. (1996). Text and corpus analysis. Oxford:Blackwell. 
Vasquez, C. (2004). 'Very carefully managed':advice and suggestions in post-observation meetings. Linguistics and Education, 15 (1-2): 33 - 58. https://doi.org/10.1016/j.linged.2004.10.004

Vasquez, C. \& Reppen, R. (2007). transforming practice: changing patterns of participation in postobservation meetings. Language Awareness, 16 (3): 153 - 172. https://doi.org/10.2167/la454.0

Waite, D. (1992). 'The Supervisor's Role in Intern Teachers' Socialization: An Ethnography of Communication of Supervisory Conferences. Journal of Curriculum and Supervision, 7 (4): 34971.

White, S. (2007). Investigating effective feedback practices for pre-service teacher education students on practicum. Teaching Education, 18 (4): 299-311. https://doi.org/10.1080/10476210701687591

Whitehead, J. (1993). The Growth of Educational Knowledge: Creating Your Own Living Educational Theories. Hyde Publications.

Zeichner, M. (1998). The structure and goals of a student teaching program and the character and quality of supervisory discourse. Teaching and Teacher Education, 4(4):349-362. https://doi.org/10.1016/0742-051X(88)90033-9

Zeichner, M. \& Liston, D. (1985). Variety of Discourse in Supervisory Conferences. Teaching and Teacher Education, 1 (2): 155 - 174. https://doi.org/10.1016/0742-051X(85)90013-7

Zeichner, M., Liston, D., Mahlios, M., \& Gomez, M. (1988). The structure and goals of a student teaching program and the character and quality of supervisory discourse. Teaching and Teacher Education, 4 (4): 349-362. https://doi.org/10.1016/0742-051X(88)90033-9 